\title{
METHODOLOGY FOR THE DYNAMIC ANALYSIS OF BUILDINGS SUBJECTED TO SEISMIC ACTIONS: INCORPORATING THE EFFECT OF NON-STRUCTURAL ELEMENTS
}

\author{
MA CARMEN GARCÍA PASTOR \& AMAYA GÓMEZ YÁBAR \\ Cype Ingenieros, Spain
}

\begin{abstract}
It is common practice to consider the enclosures and partitions of buildings as 'non-structural' elements and, consequently, neglect the rigidity and resistance they provide in the analysis of the structure against gravitational loads. However, this simplification is not always on the safe side when it comes to analysing the behaviour of the structure against horizontal earthquake loads. When a partition has not been isolated from the concrete frame surrounding it, both systems interact in the presence of seismic action. This effect increases the lateral stiffness of the frame and can cause various problems such as torsion in the building, soft-storey effect or an increase in the seismic forces. The vast majority of seismic standards establish that it is necessary to consider the influence of non-structural construction elements that can develop sufficient rigidity and resistance to modify the conditions of the structure, and that they must be taken into account when generating the structural analysis model. For this reason, CYPE Ingenieros S.A., in collaboration with the International Centre for Numerical Methods in Engineering (CIMNE), has developed a software tool that incorporates a model and a calculation methodology that allows us to consider the effects of the 'frame-masonry wall' interaction in seismic situations, in a more realistic way, and also, retain reasonable calculation duration times. Finally, presented below are the results from having applied the software tool to several calculation examples, which show the conclusions that have been obtained, and justify its contribution in terms of safety against seismic action.
\end{abstract}

Keywords: seismic, building, partitions, interaction, structure, level of damage.

\section{INTRODUCTION}

When the model of a building is created for its structure to be analysed, the stiffness and resistance provided by enclosures and partitions are usually neglected as these are considered to be "non-structural elements". The usual way to proceed is to include them as loads applied on the model, not as being a part of it. But as will be seen in the following examples, this simplification is not always on the safe side when it comes to analysing the behaviour of the structure against seismic action.

When a partition has not been isolated from the frame surrounding it, the two elements interact in the presence of horizontal loads. This effect increases the lateral stiffness of the frame and can generate different problems such as torsion in the building, soft storey effects or increase the seismic forces.

A non-uniform distribution of the masonry elements causes the stiffness centre to be displaced towards the zone where the partitions are located, causing torsion effects to arise in the building (Fardis et al. [1]).

When abrupt changes of stiffness occur between the floors of a building, the horizontal forces due to earthquake loads have a greater impact on the columns of floors with less stiffness. If these have not been adequately designed, the forces could cause brittle fracture in the columns, which would endanger the stability of the building, even causing it to collapse. The "soft-storey" problem usually occurs in buildings where the ground floor 
(whose height is usually greater than that of the other floors) is intended for commercial use or garages and therefore, does not contain any partitions, whilst the upper floors are used as dwellings, and so contain a high number of partitions. Even if the lower floor were to have a similar stiffness to that of the upper floors, during the first moments of an earthquake, the partitions of the lower zones of the building fracture, causing sudden changes in stiffness and hence, an irregularity in height similar to that described previously (Negro and Verzeletti [2], Álvarez Cabal et al. [3]).

The aforementioned increase in the seismic force in the framed structures is due to the fact that the partitions stiffen the frames, and reduce their natural vibration period, so the structure could enter the plateau of the seismic spectrum, thereby increasing the seismic coefficient and hence the seismic force (Hashemi and Mosalam [4]).

The vast majority of seismic standards establish that it is necessary to consider the influence of non-structural construction elements that can develop sufficient rigidity and resistance to modify the conditions of the structure, and that they must be taken into account when generating the structural analysis model. For this reason, CYPE Ingenieros S.A., in collaboration with the International Centre for Numerical Methods in Engineering (CIMNE), has developed a software tool that incorporates a structural analysis model that allows us to take into account the effects masonry walls have on the behaviour of reinforced concrete frames and incorporate their progressive failure.

The following is a brief description of the bases of the developed calculation methodology and analysis model, and the results obtained having applied them to analyse some specific cases of building structures.

\section{METHODOLOGY}

The aim of the model is to ensure the structural behaviour of the frame with masonry walls is well represented, always bearing in mind that this model must be incorporated in a structural analysis program with reasonable calculation times.

The proposed computational model simplifies the problem of being a non-linear analysis, solving it by performing an iterative technique of linear analysis in parts, following a similar method to that used for linear fracture mechanics (LFM).

\subsection{Analysis model}

An appropriate simplified formulation is proposed to calculate the behaviour of a framed structure, against horizontal forces, whose openings are closed with masonry walls, using a model that allows for an equivalent analysis to be carried out in a reduced period of calculation time. The fundamental aim is that the equivalent structure has a capacity (resistance, stiffness and ductility) similar to that of the real structure. To achieve this equivalence, diagonal bars, whose stiffness and resistance develop a force that controls the horizontal movement of the frame, are introduced in the structure, in the same way a masonry wall would do in the real frame (Fig. 1).

These diagonal bars, like the masonry wall, do not work in tension as their contribution is practically zero. Their stiffness in the direction perpendicular to the plane of the masonry is all considered as null.

The geometric properties of the equivalent diagonal (Fig. 2) are initially determined using the formulas proposed by Liauw and Kwan [5] and Stafford [6], [7], and, in a second phase, the results are adjusted to the experiment, and including the stiffness against horizontal movement (shear capacity) of the wall, proposed by CIMNE, in the formula. 

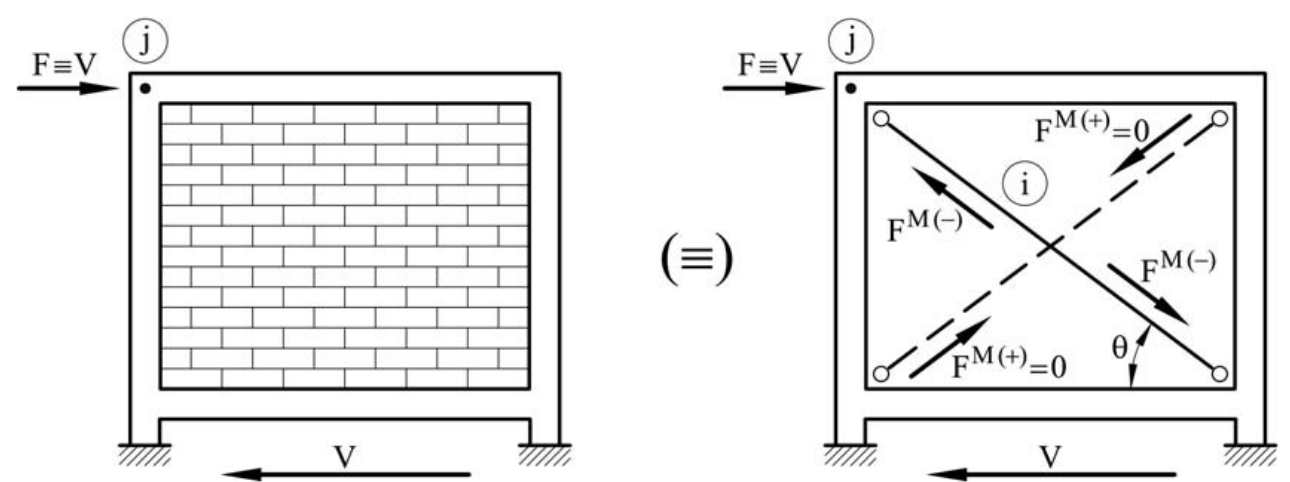

Figure 1: Simplified representation of the frame with a masonry wall.

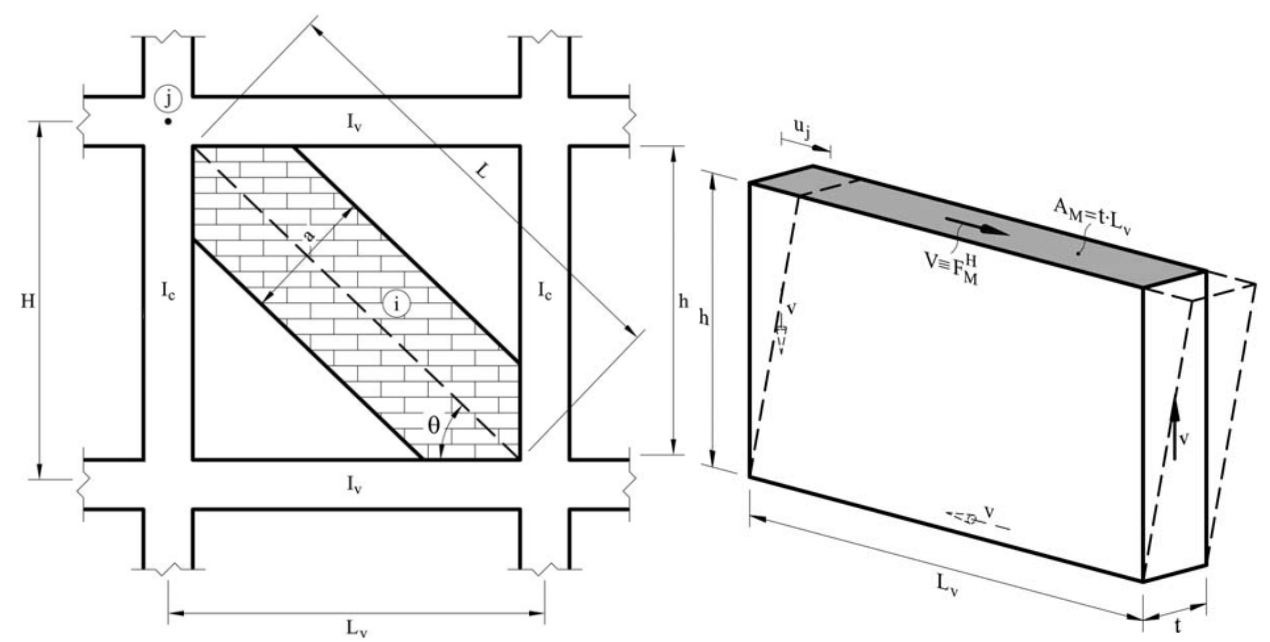

Figure 2: (a) Representation of the masonry wall diagonal contained in the frame; (b) Deformation hypothesis of the masonry wall in its plane.

The mechanical orthotropic properties of the masonry walls are determined based on a homogenisation method that is described in detail by López et al. [8] and Quinteros et al. [9], as well as on the formulas proposed by different standards (Eurocode [10], Código Técnico de la Edificación [11] - Spain, Normas Técnicas de la Construcción [12] - Mexico). Furthermore, the structural capacity of these bars is modified, in accordance with the residual resistance of the real walls, depending on the level of damage they suffer (Oliver et al. [13], Oller [14], [15], Oller et al. [16]). In other words, their capacity to resist compressive axial forces will depend on their resistance limit, which in this case depends on a local damage variable ' $d$ ', which will evolve as a function of the level of relative displacement between floors (Fig. 3). 

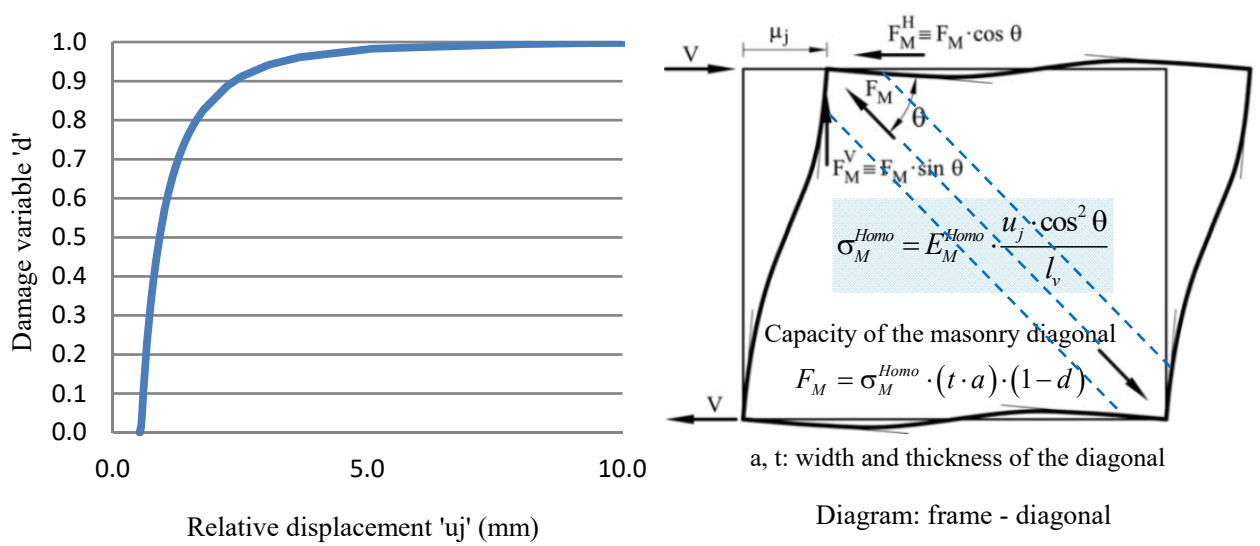

Figure 3: (a) Evolution of the damage variable 'd' vs 'uj'; (b) Capacity of the masonry diagonal.
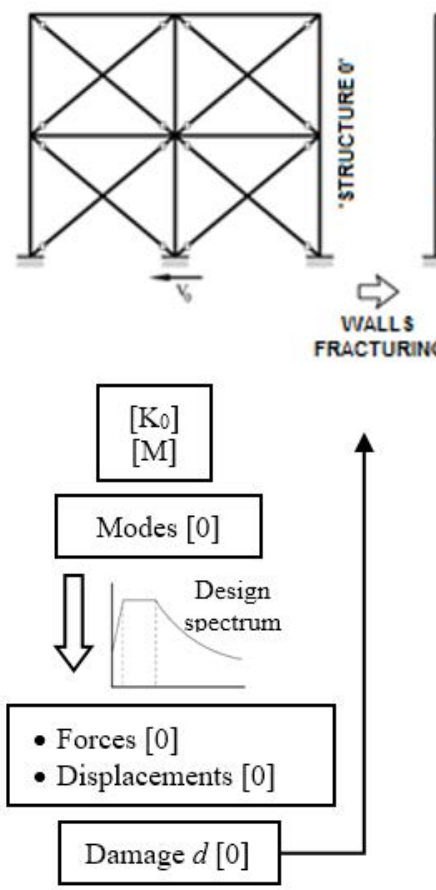

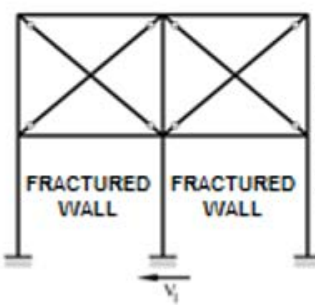

IG

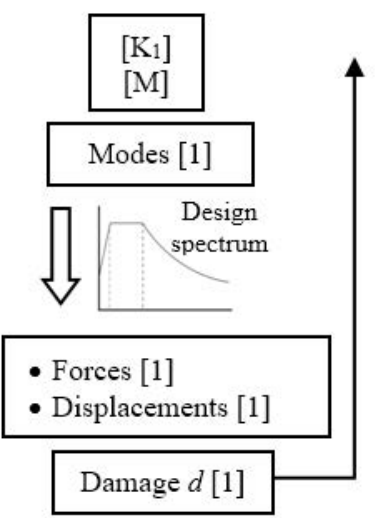

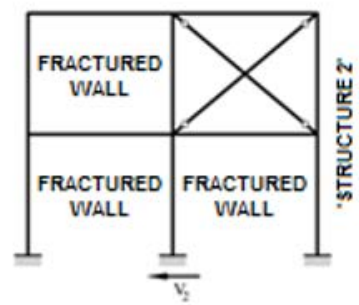
FRACTURING

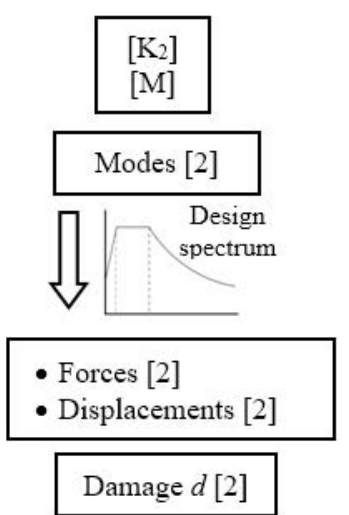

Figure 4: Diagram of the evolutionary calculation process.

\subsection{Calculation method}

The proposed method consists of solving several vibration models (Fig. 4), which correspond to different states of the partitions. A non-linear fracture problem is solved by taking the successive solutions of different linear (evolutionary) problems, which correspond to successive instants of the non-linear problem. The response, against seismic action, of each 
vibration model that has been considered, is obtained using a modal spectral analysis, assuming the materials have a linear elastic behaviour, and taking into account the stiffness provided by the construction elements, which declines progressively depending on the level of damage.

This way, it is possible to estimate, in a sufficiently precise way, how the building will really behave during an earthquake, since several linear design models which cover the different situations that can really arise, can be generated and solved.

\section{RESULTS ANALYSIS}

The explained method is incorporated into a software tool to facilitate the analysis of real building structures. The results obtained for two specific cases are shown below: the first case shows the effect produced when there is an open floor (soft storey effect), whilst the second case displays the evolution of the stiffness of the structure due to failure of the masonry during an earthquake.

The analysed structure (Fig. 5), in both cases consists of a reinforced concrete building, with 7 levels $(6+$ mechanical room), composed of frames, with spans ranging between 3 and $6 \mathrm{~m}$, and flat floor slabs with a thickness of $25 \mathrm{~cm}$. The beams are $30 \times 50 \mathrm{~cm}$ dropped beams. The height of each floor is $3.10 \mathrm{~m}$, except the ground floor which has a height of $4.00 \mathrm{~m}$.

The influence of the construction elements is taken into account by introducing $12 \mathrm{~cm}$ thick masonry walls, composed of perforated bricks with a resistance of $20 \mathrm{MPa}$ and M10 mortar. The tool generates the equivalent masonry diagonals (Fig. 6) based on the basic data that has been defined (geometry and position, and homogenised modulus of elasticity and resistance) to then create and solve the corresponding analysis models in accordance with the previously described method.
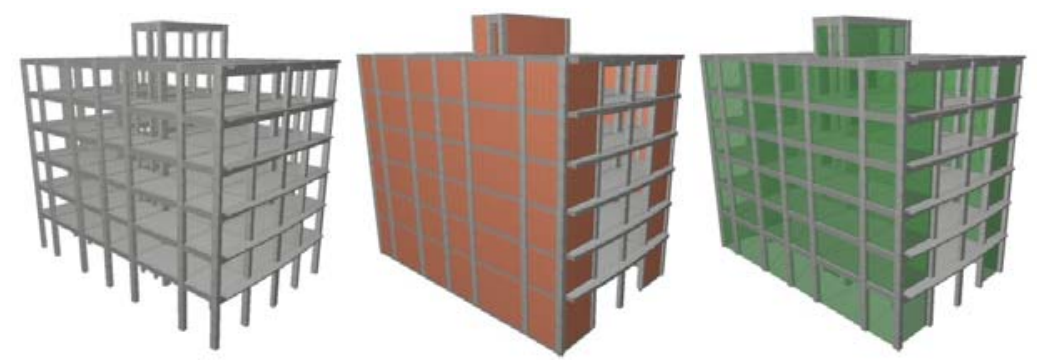

Figure 5: (a) Structure; (b) Façade and partition distribution; (c) Construction elements.

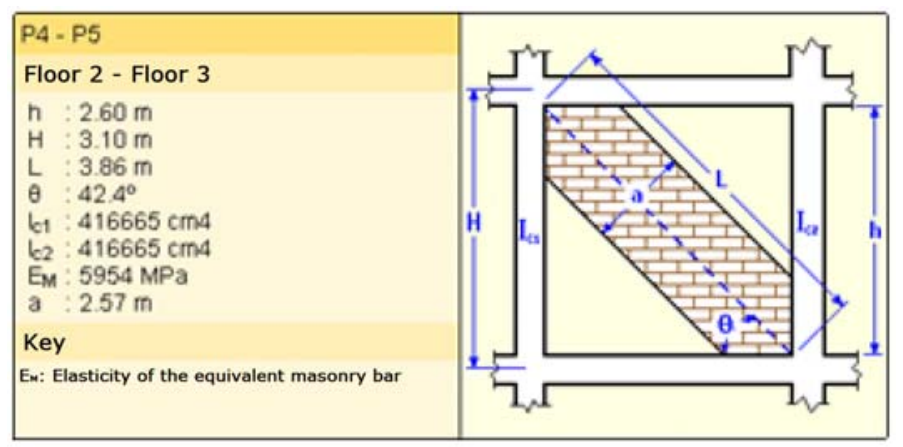

Figure 6: Data of the equivalent diagonal that is generated. 


\subsection{Case 1: open ground floor}

For this case, a uniform distribution of partitions has been introduced on all floors except the ground floor, in which none have been introduced.

Fig. 7 shows how differently the structure behaves when walls have been included in the analysis. State 0 (a) represents the deformed shape of the building for the fundamental mode, without taking into account any construction elements. The deformed shape of "State GF" (b) includes the effect of the partitions and, because of this, the values of the displacements are much smaller than those obtained in State 0 .

The periods that correspond to the vibration frequencies of the structure are also different. Represented in light blue in Fig. 8 are the period ranges for the different vibration modes of the structure. Shown with a bold line, is the period corresponding to the fundamental mode which, for the structure without partitions is $0.773 \mathrm{~s}$, while for the structure with the open ground floor, the value is $0.481 \mathrm{~s}$. This implies the value of the ordinate in the spectrum is 1.5 times greater in $(b)$ : $\mathrm{Sd}(\mathrm{g})=0.039$ for the open floor case, compared with $\mathrm{Sd}(\mathrm{g})=0.024$ for the bare structure.

Fig. 9 shows the sum of the shear forces due to seismic action at the base of the columns of each floor. These forces have been obtained by combining the results of the different modes using the CQC method.
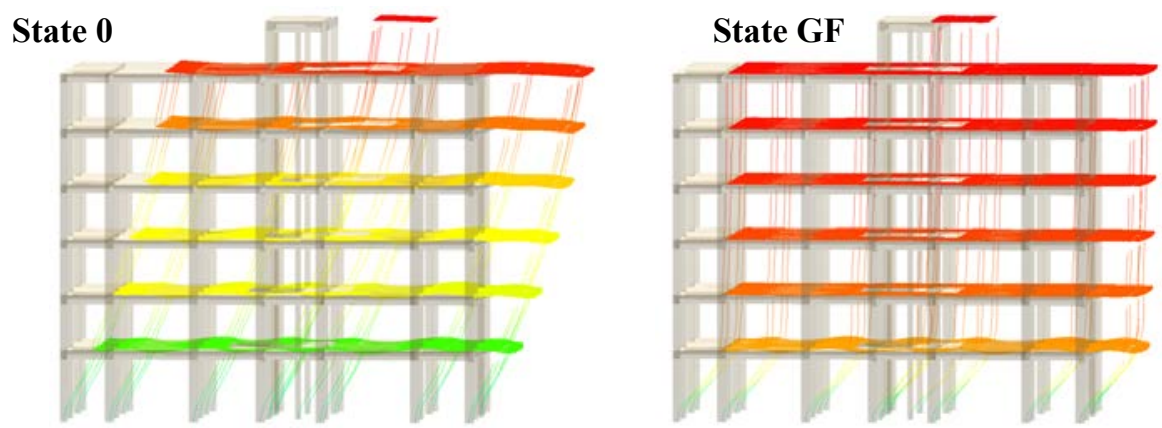

Figure 7: Deformed shape of the structure. (a) Without partitions; (b) With partitions open floor for the ground floor.
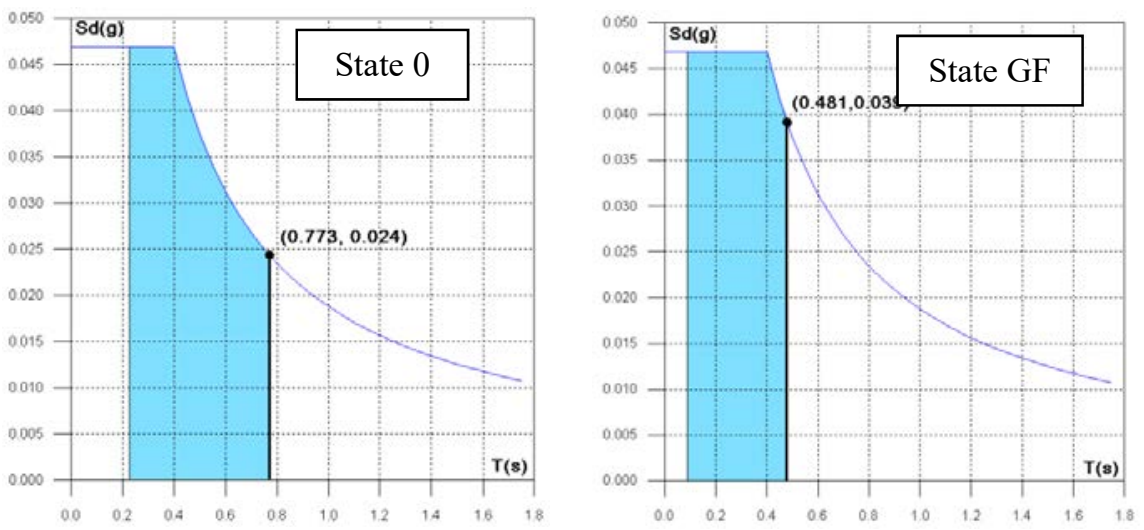

Figure 8: Modal periods. (a) Without partitions; (b) With partitions - open floor for the ground floor. 


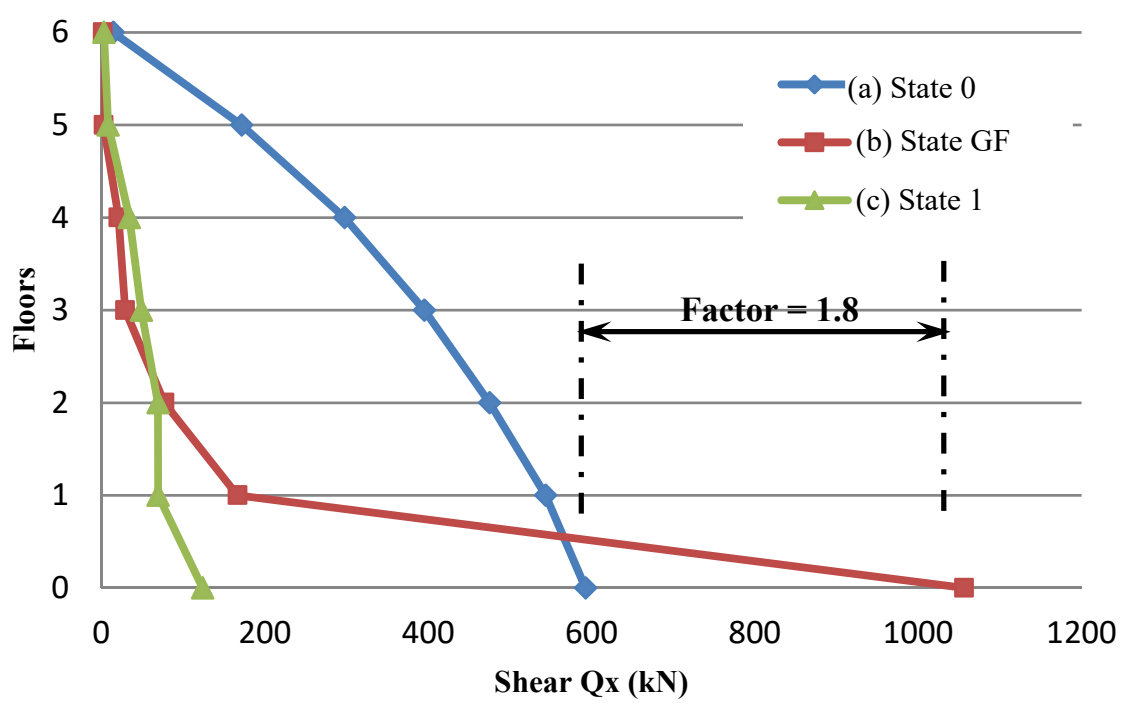

Figure 9: Shear Qx per floor.

It is clear that at the base of the building, the total shear that is obtained having considered the open floor effect (b), is practically double $(1,8$ times) than that obtained without considering the effects of the partitions (a). The forces in the remaining floors, however, are worse when the structure is bare. State 1 (c) shown below, corresponds to the results of the structure with partitions on all floors. The shear resisted by the columns is less, as it is also shared amongst the masonry elements that have been considered.

\subsection{Case II: progressive fracture of the partitions due to seismic action effects}

A uniform distribution of the partitions has been defined for all floors, including the ground floor. This case displays the evolution of the behaviour of the structure during an earthquake, due to the degradation and progressive fracture of the masonry.

The level of damage is a representative parameter of the state of fracture of the wall. Its value can vary between 0 (the wall is intact) and 1 (completely fractured), and depends on the relative displacement between floors in the direction of the wall. In the example, 6 states have been analysed, as well as State 0 , which corresponds to the structure with no construction elements. State 1 corresponds to the structure with intact partitions on all floors. In State 6 (last state that is generated, where the level of damage is stabilised), the masonry walls of the lower floors are fractured. The rest are intermediate states in which the walls have fractured progressively. Table 1 displays the evolution of the level of damage obtained for each state, of one of the walls that have been defined.

The results shown in Table 1 are obtained according to the process described below (see Fig. 4). A first modal spectral analysis is launched, including, in the stiffness of the structure, the stiffness provided by the intact masonry walls (State 1). This modal analysis causes displacements in the structure and therefore, a relative displacement between the top and bottom of each masonry wall. This relative displacement corresponds to a level of damage 'd' in the element (Fig. 3(a)). This damage parameter, for a specific wall and for each floor along which it extends, is shown in the 'State 1' column of Table 1. 
Table 1: Level of damage.

\begin{tabular}{lcccccc}
\hline Level of damage & State 1 & State 2 & State 3 & State 4 & State 5 & State 6 \\
\hline Floor 6 - Floor 7 & 0.00 & 0.00 & 0.00 & 0.00 & 0.00 & 0.00 \\
Floor 5 - Floor 6 & 0.00 & 0.00 & 0.00 & 0.00 & 0.00 & 0.00 \\
Floor 4 - Floor 5 & 0.00 & 0.00 & 0.00 & 0.00 & 0.00 & 0.00 \\
Floor 3 - Floor 4 & 0.16 & 0.41 & 0.41 & 0.41 & 0.41 & 0.41 \\
Floor 2 - Floor 3 & 0.37 & 0.69 & 0.80 & 0.87 & 0.92 & 0.94 \\
Floor 1 - Floor 2 & 0.50 & 0.85 & 0.95 & 0.98 & 0.99 & 0.99 \\
Found. - Floor 1 & 0.82 & 0.99 & 1.00 & 1.00 & 1.00 & 1.00 \\
\hline
\end{tabular}

After this analysis, the damage ' $d$ ' incurred by each wall is known. The capacity of the equivalent diagonal $\left(\mathrm{F}_{\mathrm{M}}\right)$ of the damaged wall is calculated according to the formula in Fig. 3(b). A second modal spectral analysis is launched, including, in the stiffness of the structure, the stiffness provided by the damaged walls of the first analysis (State 2). This modal analysis causes displacements in the structure, a relative displacement between the top and bottom of each masonry wall and a level of damage ' $d$ ' in the element, associated with this relative displacement. This parameter, for the wall in question and for each floor along which it extends, is shown in the 'State 2' column of Table 1.

This process is repeated successively until the value of the damage parameter of all the walls of the structures becomes stable (State 6). For each masonry wall of the structure, there is a similar table to Table 1 . The different states and series of analyses are generated automatically by the program: CYPECAD, in which the methodology that has been exposed has been implemented.

From the results, it is possible to deduce that, at first, the masonry begins to fracture at the lower floors, producing a reduction in stiffness in that zone and, therefore, an increase in the displacements which causes greater fractures. In the following instants, the partitions of the ground floor fracture completely (damage 1.00) and the remaining partitions fracture progressively in ascending order, where the masonry at the top floors suffers little or no damage.

It can be seen that the results of the proposed design model clearly reflect the damage buildings usually suffer in real earthquakes. They also coincide with the damage obtained experimentally by Negro and Verzeletti [2].

As the resistance capacity of the masonry walls is reduced due to the progressive fracturing process, the displacement values gradually increase. Fig. 10 shows the deformed shapes of the building for different states. State 0 does not consider any construction elements; State 1 corresponds to the structure with intact partitions on all floors; the remaining states take into account the influence of the masonry for the different fracture levels, out of which, states 3 and 6 are represented, which correspond to when the shear is greatest in the columns of the ground floor and first floor respectively.

In the same way, as in the previous example, Fig. 11 represents the sum of the shear forces due to seismic action at the base of the columns for each floor. For the ground floor and first floor, the forces that are produced in states 3 to 6 (Table 2) are greater than those that would be obtained if no partitions were to be included in the model (State 0 ). 


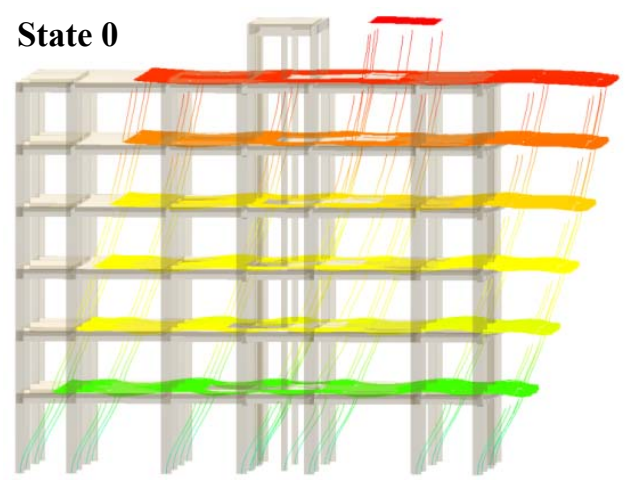

(a) with no partitions

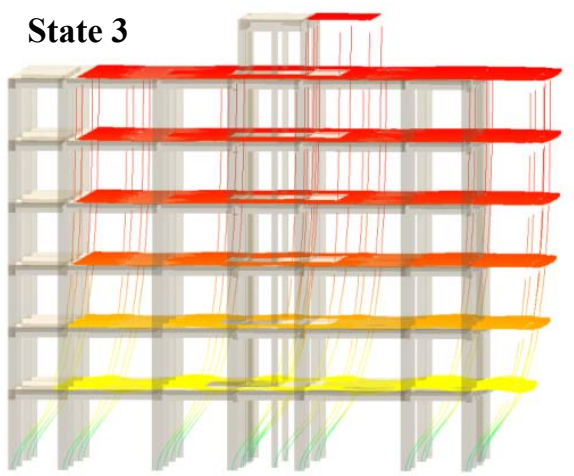

(c) Intermediate state (fractured partitions)

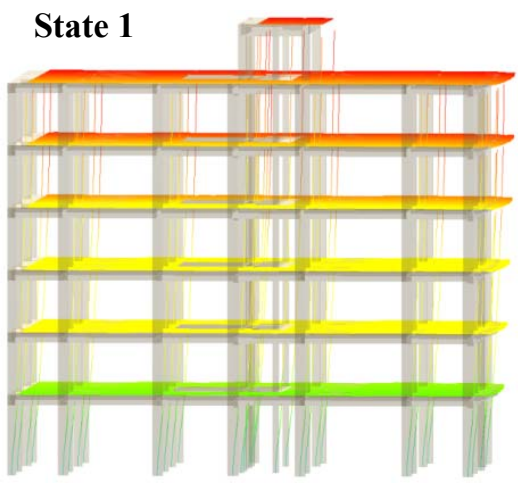

(b) with partitions

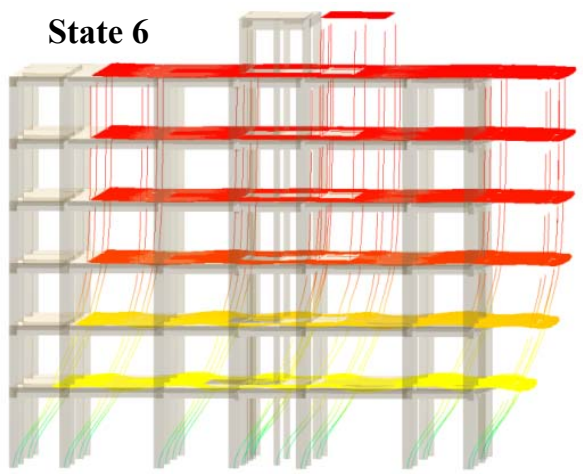

(d) Final state (fractured partitions)

Figure 10: Deformed shape of the structure. (a) With no partitions; (b) With partitions; (c) Intermediate state (fractured partitions); (d) Final state (fractured partitions).

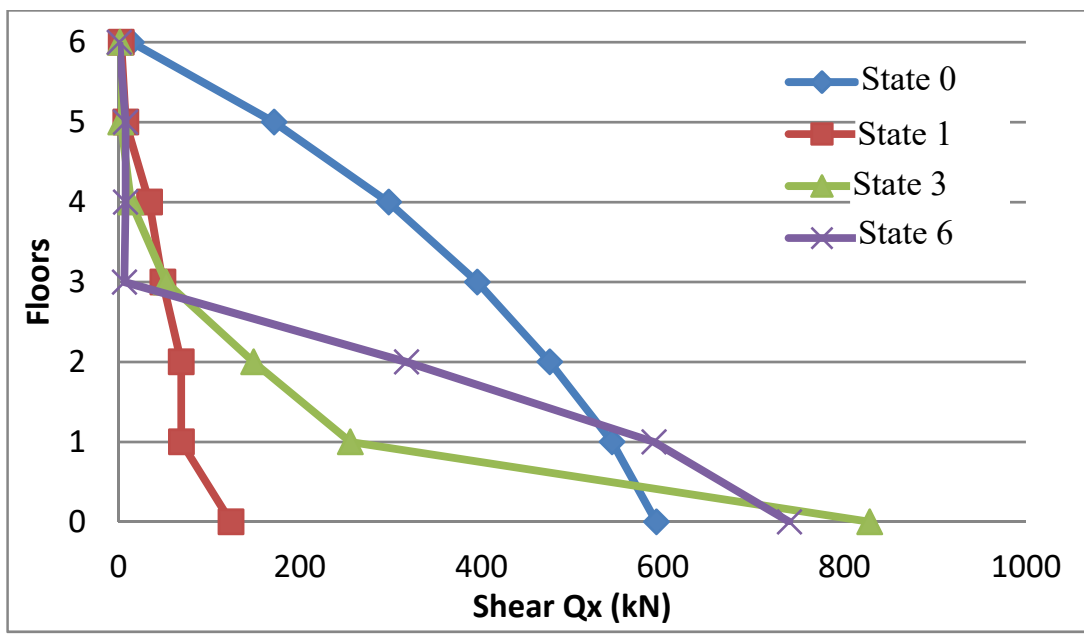

Figure 11: Shear Qx per floor. 
Table 2: Shear Qx per floor.

\begin{tabular}{lrrrrrrr}
\hline $\begin{array}{c}\text { Shear Qx } \\
(\mathbf{k N )}\end{array}$ & \multicolumn{1}{c}{ State 0 } & \multicolumn{1}{c}{ State 1 } & \multicolumn{1}{c}{ State 2 } & \multicolumn{1}{c}{ State 3 } & State 4 & State 5 & \multicolumn{1}{c}{ State 6 } \\
\hline Fl.6-Fl.7 & 14,234 & 2,873 & 2,598 & 1,457 & 1,078 & 0,895 & 0,807 \\
Fl.5- Fl.6 & 171,460 & 7,962 & 2,643 & 2,507 & 5,038 & 6,720 & 7,712 \\
Fl.4 - Fl.5 & 297,594 & 34,063 & 30,266 & 13,740 & 9,167 & 7,973 & 7,754 \\
Fl.3- Fl.4 & 395,323 & 48,728 & 61,305 & 52,421 & 35,122 & 18,811 & 6,467 \\
Fl.2- Fl.3 & 475,143 & 69,091 & 122,715 & 148,858 & 180,846 & 247,457 & 317,398 \\
Fl.1 - Fl.2 & 543,807 & 69,184 & 110,942 & 255,491 & 478,456 & 573,390 & $\mathbf{5 9 0 , 2 5 2}$ \\
Found. - & 592,599 & 123,832 & 511,703 & $\mathbf{8 2 7 , 8 2 4}$ & 797,696 & 757,932 & 739,372 \\
Fl.1 & & & & & & \\
\hline
\end{tabular}

\section{CONCLUSION}

In view of the results that have been obtained, it is possible to conclude that the proposed design model provides a good representation of the real behaviour of building structures in seismic situations. Thanks to the software tool that has been developed, it can easily be applied and incorporated in the design of common building structures.

It is evident how important it is to consider the effects of the masonry walls if there are any open floors, as the forces in the columns of that floor are much greater compared to the forces that are obtained with a bare structure.

To cover this effect, some seismic codes propose that, if a more precise analysis is not carried out, the forces be multiplied by a factor ranging between 1.5 and 2.5. These values match those obtained upon applied the proposed method.

It is also possible to deduce from the model, and as occurs in reality, that during the first instants of a moderate earthquake, the masonry walls of the lower floors fracture. This produces a similar effect to that of the soft storey effect and therefore, the columns of these floors should be designed to resist greater forces than those calculated without including any partitions. The proposed model predicts how the fractures and progressive failure of the masonry walls are going to occur, and estimate the forces of the structural elements for the worst-case situation.

\section{ACKNOWLEDGEMENTS}

The advances and conclusions presented in this paper are part of the results obtained by CYPE Ingenieros S.A. in collaboration with the International Center for Numerical Methods in Engineering (CIMNE) for the "Methodology for the dynamic analysis of buildings exposed to seismic action, with the incorporation of non-structural elements and the development of a software tool with BIM model". It has been possible to undertake this project thanks to the financing offered by the CDTI (Centre for the Development of Industrial Technology) for $\mathrm{R}+\mathrm{D}+\mathrm{I}$ project and would not have been carried out without the knowledge and help provided especially by Sergio Oller and Alex Barbat.

Some of the figures used to aid in the understanding of the design model and analysis methodology have been extracted from documents provided by CIMNE in the development of the project.

\section{REFERENCES}

[1] Fardis, M.N., Bousias, S.N., Franchioni, G. \& Panagiotakos, T.B., Seismic Response and Design of RC Structures with Plan-Eccentric Masonry Infills. Earthquake Engineering and Structural Dynamics, 28(2), pp. 173-191, 1999. 
[2] Negro, P. \& Verzeletti, G., Effect of Infills on the Global Behavior of RC Frames: Energy Considerations from Pseudo-Dynamic Tests. Earthquake Engineering and Structural Dynamics, 25(8), pp. 753-773, 1996.

[3] Álvarez Cabal, R., Díaz-Pavón Cuaresma, E. \& Rodríguez Escribano, R., El Terremoto de Lorca. Efectos en los edificios. Consorcio de Compensación de Seguros, 2013.

[4] Hashemi, A. \& Mosalam, K.M., Seismic Evaluation of Reinforced Concrete Buildings Including Effects of Masonry Infill Walls. PEER Report 2007/100.

[5] Liauw, T. \& Kwan, K., Non-Linear Behaviour of Non-Integral Infilled Frames. Computers \& Structures, 18(3), pp. 551-560, 1984.

[6] Stafford, S., Lateral Stiffness of Infilled Frames. Proceedings of the American Society of Civil Engineering, Journal of Structural Division, 88(ST6), pp. 183-199, 1962.

[7] Stafford, S., Behaviour of Square Infilled Frames. Proceedings of the American Society of Civil Engineering, Journal of Structural Division, 92(ST1), pp. 381-403, 1966.

[8] López, J., Oller, S., Oñate, E. \& Lubliner, J., A Homogeneous Constitutive Model for Masonry. International Journal for Numerical Methods in Engineering, 46, pp. 16511671, 1999.

[9] Quinteros, R., Oller, S. \& Nallim, L., Nonlinear Homogenization Techniques to Solve Masonry Structures Problems. Composite Structures, 94, pp. 724-730, 2011.

[10] Eurocode 6 - Design of masonry structures. Part 1-1: General rules for reinforced and unreinforced masonry structures, 1996.

[11] Código Técnico de la Edificación. Documento Básico Se-F Seguridad Estructural: Fábrica, 2006.

[12] Normas Técnicas Complementarias para Diseño y Construcción de Estructuras de Mampostería, 2004.

[13] Oliver, J., Cervera, M., Oller, S. \& Lubliner, J., Nonlinear Isotropic Damage Models and Smeared Crack Analysis of Concrete. Proceedings of the 2nd International Conference on Computer Aided, Analysis and Design of Concrete Structures, pp. 945957, 1990.

[14] Oller, S. Fractura Mecánica un Enfoque Global. Centro Internacional de Métodos Numéricos en Ingeniería (CIMNE), 2001.

[15] Oller, S. Análisis y Cálculo de Estructuras de Materiales Compuestos. Centro Internacional de Métodos Numéricos en Ingeniería (CIMNE), 2002.

[16] Oller, S., Car, E. \& Lubliner, J., Definition of a General Implicit Orthotropic Yield Criterion. Computer Methods in Applied Mechanics and Engineering, 192(7-8), pp. 895-912, 2003. 